\title{
Research on Internet of Things-based Virtual Logistics Enterprises Performance Evaluation
}

\author{
Hong-Xia ZHANG ${ }^{1, a,{ }^{*}}$
}

${ }^{1}$ School of Economics and Management Shenyang University of Chemical Technology Shenyang, China

ahhsyln@126.com

${ }^{*}$ Corresponding author

Keywords: Virtual Logistics Enterprise, Internet of things, Virtual Performance evaluation.

\begin{abstract}
Virtual Logistics Enterprise is a dynamic alliance in the logistics industry. Virtual Logistics Enterprise transaction process is virtualized. The members of Virtual Logistics Enterprise dispersed in different regions. And during the project period, they do not belong to any organization. This makes the traditional performance evaluation methods are difficult to apply to this new organizational structure. Therefore, the virtual logistics enterprise performance evaluation will focus primarily on evaluate the project participants and member business as a whole. Formation of virtual logistics enterprise is based on the reality of the logistics activities. Therefore each member in the project implementation process contact is very important. Application of Internet of Things technology provides great room for maneuver to achieve modern large and complex logistics activities. Internet of Things technology provides specific technical and security applications for the virtual logistics enterprise project completion. Internet of Things technology can achieve the integrity of the members of the enterprise performance evaluation. Virtual Logistics Enterprises can achieve multi-session, multi-level, multi-angle performance evaluation.
\end{abstract}

\section{Introduction}

Virtual Logistics Enterprise is the latest product of the development of the logistics industry. Virtual Logistics Enterprise is also the great achievements of modern logistics industry development. Virtual Logistics Enterprise is an operation in a dynamic economic organization. Virtual Logistics Enterprise is composed of many stakeholders. They will achieve many objectives, including sharing of benefits, sharing of information, sharing of responsibilities, integration of operations and rational allocation of functions, etc. They organize the appropriate resources for specific projects to provide logistics services. After the project is completed, the self-organization of the virtual enterprise alliance will be dissolved. When there is a market opportunity next time, different members will then participate in the composition new virtual logistics enterprise according to the market demands.

Virtual Logistics Enterprise transaction process is virtualized. The member enterprise dispersed in different areas. During the execution of the project, each enterprise can not just leave this organization. This makes the traditional performance evaluation methods are difficult to apply to this new organizational structure. Therefore, the virtual logistics enterprise performance evaluation will focus primarily on evaluate the project participants and member business as a whole. Formation of virtual logistics enterprise is based on the reality of the logistics activities. Therefore each member in the project implementation process contact is very important. Application of Internet of things technology provides great room for maneuver to achieve modern large and complex logistics activities. Internet of things technology provides specific technical and security applications for the virtual logistics enterprise project completion. Internet of Things technology 
can achieve the integrity of the members of the enterprise performance evaluation.

\section{About Virtual Logistics Enterprise}

With the world economy and information network technology rapid development, logistics industry will also be growing. Logistics industry is developing in the direction of the remote and internationalization. Some traditional logistics operation has become very complicated. These large or complex logistics operations need the support of a variety of conditions. Such a task has been impossible to complete determined by single enterprises resource fixity. Virtual Logistics Enterprise is a dynamic alliance of logistics industry. Virtual Logistics Enterprise is an organization formed by a plurality of entities. Resources and core capabilities of these entities organization are autonomous and independent. They formed a virtual logistics enterprise structure in mutual learning and mutual adaptation process. The trading of virtual logistics enterprise process is virtualization. Such a transaction has many of the characteristics. Such as dynamic, loose, temporary, complementary and so on.

In the modern market competitive environment, virtual logistics companies can effectively integrate social resources as much as possible quickly within a short time. In this way, virtual logistics enterprises can capture market opportunities and achieve reduce the logistics costs and increase customer satisfaction. So that it can improve the overall competitiveness of this dynamic alliance.

\section{About Virtual Logistics Enterprise Performance Evaluation}

However, virtual logistics enterprise brings a large number of benefits to the individual member enterprises, there are also some new problems and potential risks in this dynamic organization. The internal and external virtual logistics enterprise has some non uncertainties. This will cause the virtual logistics enterprise can not reach a preset objectives, and even lead to the eventual loss of benefits. In the process of virtual logistics enterprises to achieve its stated objectives of the project, it must strengthen the construction of performance management and performance evaluation system in the whole dynamic organization.

However, each member of Virtual Logistics Enterprise are separate entities, each member has their own business objectives and performance evaluation system. Traditional performance evaluations of enterprises are managing their own internal business. The subject be evaluated is a part of the enterprise. Therefore, the performance evaluation system existed in the reality of enterprises can constraint the evaluated people. And the enterprise can always get each being realistic performance and historical data of the evaluated one. However, the virtual logistics enterprise is itself dynamic. In the process of completion of the project, there is only one coordination and cooperation of the participating body between each other. This will not be a longterm cooperative relations, so virtual logistics enterprise can not achieve long-term performance evaluation system. Therefore virtual logistics enterprise needs to build new real-time performance evaluation system. This requires real- time grasp the situation of the parties involved in specific logistics business and evaluate its ability to complete the objectives and status.

In the virtual logistics enterprises, the daily operations of each member enterprises are usually in a different environment. The value added of the actual logistics business operation of virtual logistics enterprise is mostly invisible. Except for the way business is paperless, such as share information in the strategic alliance, contacts of the members face to face or online, etc. This makes the performance evaluation of the dynamic alliance can not be implemented as traditional 
performance management process. Therefore, in the ordinary course of the project implementation process, performance evaluation of each participant can be effectively completed through effective monitoring and consolidation of various business processes. This can optimize the use of resources among members of the business logistics services. Logistics business object implementation is tangible. This is one of the biggest features of the logistics business. Virtual Logistics Enterprise effectively monitors actual business by the logistics business objects. According to the actual situation of each specific business and logistics of each participant, Virtual Logistics Enterprises evaluate the actual performance of the participating subjects with determined virtual performance evaluation indicators.

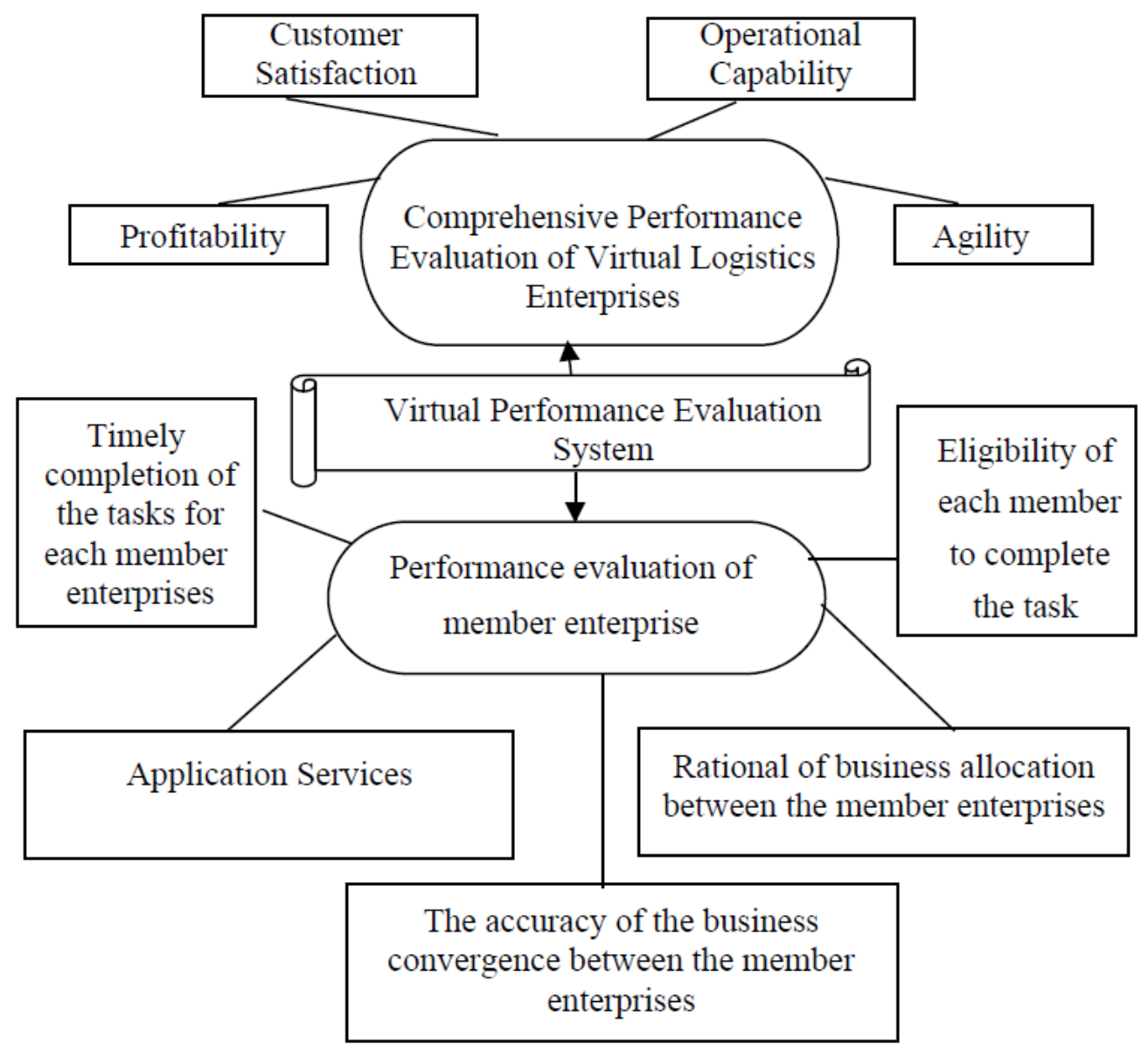

Fig. 1. Virtual performance evaluation system

\section{Internet of Things and Virtual Logistics Enterprises}

Internet of Things is the relationship between things and things. The core and foundation of Internet of things is still modern Internet architecture. Internet of Things is a network Extended and expanded the Internet-based technologies. Each client's operations can be extended and expanded to any goods and item and exchange information and communications. Internet of Things can integrate a variety of application technology, such as IntelliSense, identification technology and pervasive computing technologies. Internet of Things technology called third wave of the world information industry development after the computer, the Internet.

Internet of Things is usually considered to be applied expanding the Internet. More often Internet of Things technology can achieve the integration of specific services and applications. After the Internet of Things technology services in the logistics business, many of logistics business process information can be dynamically perceived and recorded, such as logistics environment, logistics 
carrier vehicle, logistics facilities, attributes and status of the transshipment cargos etc. Then the intelligent control of logistics can be realized.

The goal of Internet of Things is to achieve intelligent control between things and things. The Internet of Things technology of virtual logistics enterprises promotes the optimization and integration of all aspects of the logistics business. Advanced information technology in Internet of Things has brought benefits to the cooperation among member enterprises, including logistics efficiency, logistics cost control and so on. Internet of Things improves the information level of the member enterprises and related fields as a whole. With the intelligence level of virtual logistics business demands rising, Internet of Things not only enriched the existing logistics business system, but also changed the existing logistics business processes.

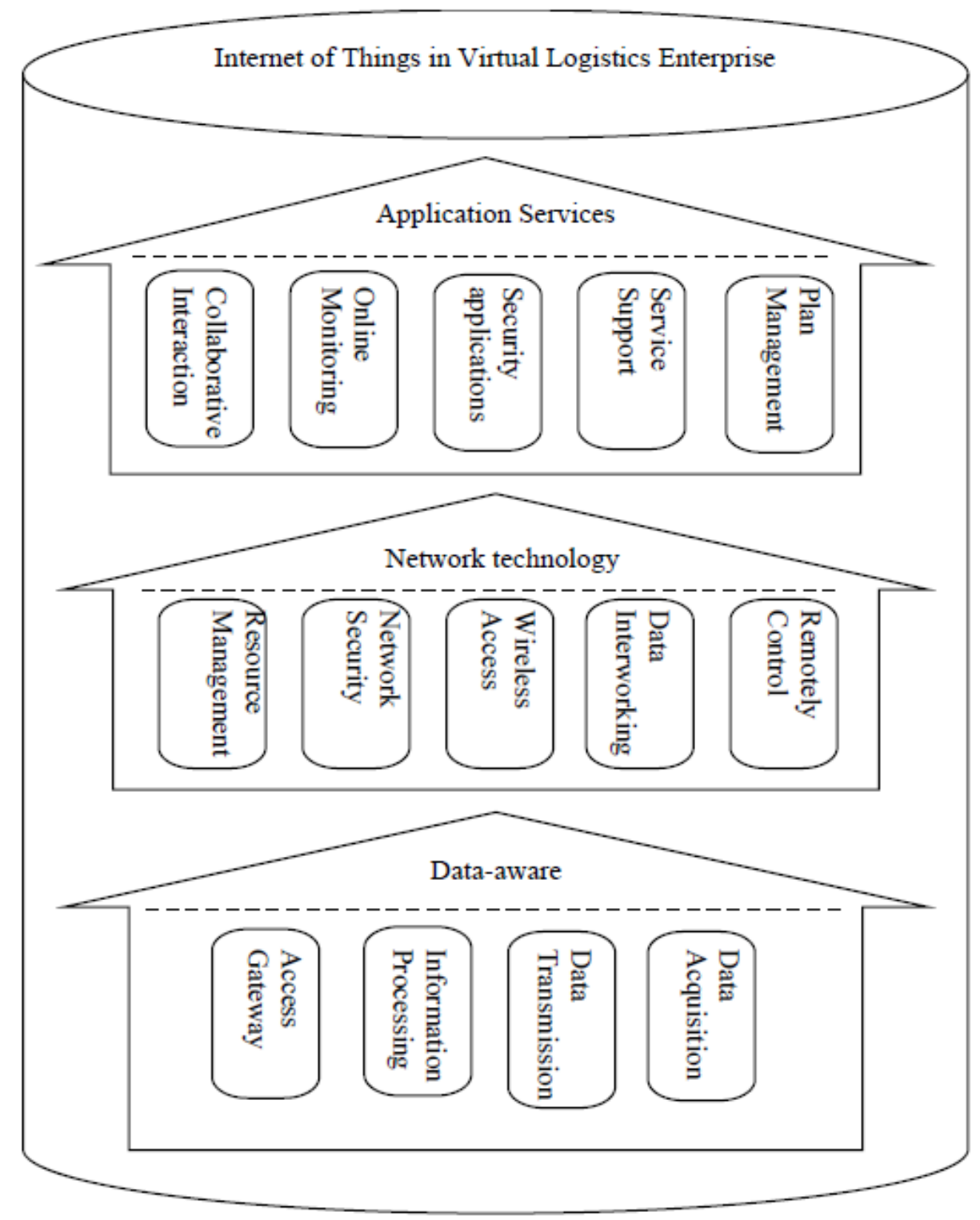

Fig. 2. Internet of things in virtual logistics enterprise

\section{The Impact of Internet of Things Technology on Virtual Logistics Enterprise Performance Evaluation}

Virtual Logistics Enterprises formation conditions are based on the needs of the market. When the market opportunities generated virtual logistics enterprises will integrate resources to complete 
specific logistics projects and provide logistics services to meet market needs. After determining the logistics services, the Union's core enterprises will reasonably allocate tasks according to the specific circumstances and the ability of the project members of the Union. Each sub-task can be performed by a member business. It can also be jointly completed by a number of member companies. In the process of specific logistics projects completed, Virtual Logistics Enterprise will always compose a close collaboration as a whole focus on logistics project requirements previously determined. Therefore, in process of the project, the participating companies will participate closely together to achieve the goals of logistics projects. But they will not maintain long-term stable cooperative relations. At the end of the project these companies will restore the original status of independent operators. So for an independent enterprise, its daily management activities are sustained long-lasting. These tasks include enterprise performance management and performance evaluation, etc. Performance evaluation internal is conducted to achieve its own development needs. In most cases, such a performance evaluation can not fully meet the needs of virtual logistics enterprise. Virtual logistics enterprises must build up their own virtual performance evaluation system.

The establishment of virtual logistics enterprises relies on reality logistics demand of market, so that the performance management and performance evaluation process of virtual logistics enterprise should follow the requirements of the logistics project. The purpose of constructing a virtual logistics enterprise is to integrate the appropriate partners by the core enterprise. It also provides their high cost - effective logistics services to achieve the overall best. This means that virtual logistics enterprise needs to carry out certain of the participating enterprises performance evaluation. Therefore virtual logistics enterprises must build up the performance evaluation system to meet the whole Union's tasks. The operational activities of Virtual Logistics Enterprise are combined with the specific logistics projects. Its performance evaluation of each participant must also around the specific operation of the project. Virtual performance evaluation system should be developed based on the logistics of project implementation. Establishment of virtual performance evaluation system should be based on the actual business of virtual logistics enterprise. The actual business of virtual logistics enterprise closely linked with the logistics process. So the virtual logistics enterprises must promptly and accurately grasp the actual logistics process. This is especially important for virtual performance evaluation.

Internet of Things will be applied to the management process of the virtual logistics enterprise. This allows project management logistics process intelligence. Through the sensors and other Internet of Things technology, Virtual Logistics Enterprise can real-time monitor the various business processes and each participant and intelligent analysis the collected information to ensure proper completion of the logistics project. Internet of Things technology will also perform the same role in the performance evaluation process in virtual logistics enterprise. Virtual performance evaluation is no longer the traditional ex-post evaluation. As a service organization in the market demand, virtual logistics enterprises can not accept such ex-post performance evaluation. The real tasks completed status of the participation enterprise of virtual logistics enterprise logistics business is the most reliable and timely. Thus Internet of things used in virtual performance evaluation daily work to improve actual monitoring and evaluation for each participant. It also can be achieved by Internet of Things technology to get the first-hand information of virtual performance evaluation system several elements.

Internet of Things technology will help virtual logistics enterprise to improve the construction and implementation of virtual performance evaluation system. Internet of Things provides effective support for the logistics business process of virtual logistics enterprise. Also Internet of Things 
plays a role in the process of virtual performance evaluation gradually to mature.

\section{References}

[1] Daniel D. Giusto, Antonio Lera, Giacomo Morabito, Luigi Atzori, The Internet of Things, Springer-Verlag New York Inc., New York, 2010.

[2] Cuno Pfister, Getting Started with the Internet of Things: Connecting Sensors and Microcontrollers to the Cloud, O'Reilly Media, Inc. California, 2011

[3] Robert Bacal, Performance Management, McGraw-Hill Professional , New York, 2012 [4] http://wiki.mbalib.com/wiki/

[5] http://baike.baidu.com/ 